\title{
RAPTOS, DEFLORAMENTOS, VIOLÊNCIA E RELAÇÕES DE PODER NA AMAZÔnia ACREANa (1904-1920)
}

\section{Francisco Bento da Silva ${ }^{1}$}

RESUMO: O presente trabalho traz uma abordagem sobre a questão da criminalidade no Acre Federal, principalmente envolvendo os chamados crimes contra a honra e a moral. Utilizamos como fonte documental relatos de jornais, processos criminais e obras literárias. Tais crimes, reais ou ficcionais, trazem a marca das relações de poder envolvendo gênero, geralmente nos casos em que ocorriam disputas entre homens pela mulher; vinganças onde a mulher é a vítima, devido suspeitas, fundadas ou não, de traição; vinganças de parentes masculinos para defender a honra das mulheres do núcleo familiar quando maculada, entre outras práticas correlatas de uma sociedade marcada pelos "rituais de masculinidade", com vem afirmar McClintock (2010) quando fala do contexto colonial e imperial. Portanto, estudar tais questões em áreas de fronteiras, de enfrentamentos multifacetados entre gentes de oriundas de tantos lugares, com interesses diversos e em entrechoques, nos permite revelar práticas e identidades muitas vezes submersas nas narrativas tradicionais.

PALAVRAS CHAVE: Violência. Crime. Mulher. Acre. Identidade.

\section{Introdução}

Neste trabalho temos por objetivo analisar alguns casos de crimes classificados como atentados à honra, à moral e à honestidade ocorridos no Território Federal do Acre entre os anos de 1904 e 1920. A legislação criminal em vigor na época no Brasil, o Código Penal de 1890, em seu preâmbulo intitulado "Dos crimes contra a segurança da honra e honestidade das famílias e do ultraje público ao pudor", tipificava sete tipos de crimes nesta categorização: violência carnal (artigo 266), defloramento (artigo 267), estupro (artigo 269), lenocínio (artigo 277), adultério (artigo 279), atentado ao pudor (artigo 282) e rapto (artigo 270).

A violência carnal era algo que poderia ocorrer contra pessoas de ambos os sexos, pois considerava crime atentar contra o pudor de

${ }^{1}$ Doutor em História, Professor da Universidade Federal do Acre. 
uma pessoa com uso de violências ou ameaças com a finalidade de saciar "paixões lascivas ou por depravação moral". Este crime era punido com pena que variava de um a seis anos de prisão. Se a vítima fosse menor de idade a pena também era a mesma, desde que houvesse apenas a chamada libidinagem (FARIA, 1913). O defloramento era um crime que incorria como vítima a mulher de menor idade que fosse considerada ludibriada pela figura masculina com sedução, engano ou fraude. A punição para este tipo de crime variava de um a quatro anos de prisão celular (FARIA, 1913). Já o estupro era sexo forçado com qualquer mulher, fosse ou não virgem. Para este último caso, o que variava na periculosidade do crime era se a mulher fosse considerada "honesta". O estupro contra mulher "honesta" (virgem ou não) tinha pena que variava de um a seis anos. Já o mesmo crime cometido contra mulheres consideradas "públicas ou prostitutas", o réu era condenado de seis meses a dois anos de prisão (FARIA, 1913). Isso demonstra uma forte carga moral e machista que minorava o mesmo crime se cometido contra uma mulher considerada "desonrada" ou prostituta, por exemplo. Com bem diz Anne McClintock, a "erótica da conquista é também uma erótica da subjugação" (MCCLINTOCK, 2010, p. 48).

Ao crime de lenocínio incorria quem excitasse, favorecesse ou facilitasse a "a prostituição de alguém para satisfazer desejos desonestos ou paixões lascivas de outrem”. O adultério era outro crime no qual a vítima na prática era exclusivamente a mulher, pois a infidelidade conjugal só era punida quando realizada pela esposa, embora o Código Penal apontasse para a dualidade de gênero no cometimento desse tipo de crime. A pena era de prisão celular que variava de um a dois anos. "S $1^{\circ}$ ) Em igual pena incorrerá: O marido que tiver concubina teúda e manteúda; A concubina; O co-réo adultero" (FARIA, 1913). $\mathrm{O}$ atentado ao pudor era visto como ofensa aos chamados bons costumes e o pudor com "exibições impudicas, atos ou gestos obscenos" realizados em lugar público.

Mais complexo e cheio de nuances era o crime de rapto, também cometido exclusivamente pela figura masculina. Considerava-se rapto tirar mulher "honesta" do seu lar doméstico para fins considerados libidinosos, não importando se solteira, casada ou viúva, fazendo uso de sedução, violência ou emboscada mesmo que não se verificasse "a satisfação dos gozos genésicos" A pena simples variava de um a quatro anos de reclusão. Os agravantes da pena 
eram vários: se parente ou conhecido da vítima, se ocorresse estupro, violência, entre outros (FARIA, 1913). E mesmo que a vítima do rapto tivesse mais de 16 e menos de 21 anos e consentisse a prática, isso não anulava a culpa criminal do raptor.

Porém, havia um atenuante que juntava os crimes de rapto, estupro de defloramento em um só e dizia o seguinte:

Art. 276. Nos casos de defloramento, como nos de estupro de mulher honesta, a sentença que condenar o criminoso o obrigará a dotar a ofendida. Parágrafo único. Não haverá logar imposição de pena si seguir- se o casamento a aprazimento do representante legal da ofendida, ou do juiz dos órfãos, nos casos em que lhe compete dar ou suprir o consentimento, ou a aprazimento da ofendida, si for maior (FARIA, 1913).

$\mathrm{Na}$ Amazônia acreana, existem inúmeros registros escritos e orais e de que em diversas situações, o rapto era uma ação combinada entre as duas partes, vitima e réu, para forçarem a realização de uma união formal quando os familiares da raptada se colocavam contra a relação amorosa e conjugal dos pretendentes. Quando o rapto era realizado, os parentes masculinos da mulher em muitos momentos eram encarregados de vingar com sangue (caso não aceitassem a união) ou obrigar o raptor a casar com a raptada, o que era mais frequente. Mas existem também relatos de crimes passionais cometidos pelo homem que se sentia rejeitado nas suas investidas amorosas com intuitos conjugais ou apenas de aventuras amorosas passageiras.

Em sociedades fortemente pautadas nos princípios da masculinidade, era motivo de chacota um homem ser rejeitado e não reagir com "hombridade" (SILVA, 2013). Em sociedades onde o espaço público é essencialmente masculino, tal como o exercício do poder político, da posse da terra e do dinheiro, "as mulheres são figuradas como propriedades pertencentes ao homem” (MCCLINTOCK, 2010, p. 58).

A historiadora Christina Scheibe Wolff (1999), em seu livro "Mulheres da floresta", ao estudar a realidade do Alto Juruá no Acre, entre os anos de 1890 e 1945, aponta que a violência era algo que atravessa todas as 
relações sociais na sociedade dos seringais e que se manifestava de múltiplas formas. Tinha vários significados e motivações: autoridade, coragem, hierarquia, controle, resistência e revolta. Por isso, violência e poder eram elementos frequentemente associados, algo entranhado nos costumes e na cultura da sociedade local e essas práticas ditavam muitas vezes o senso de justiça compartilhado pela maioria. Um a violência marcada indelevelmente pelo signo da masculinidade, que estava presente tanto na mentalidade masculina quanto na feminina (WOLFF, 1999, p. 195-241).

Esta autora entende que as regras de convivência nos seringais amazônicos em muito eram herdadas das práticas sociais dos ditos sertões do nordeste, de onde vieram muitos migrantes para explorarem o boom da borracha natural em terras amazônicas. Eram comportamentos vinculados às questões de honra, que em grande medida estava associada à proteção e domínio da figura feminina pelo homem. Nesse contexto, certas situações relacionadas à honra tinham que ser necessariamente resolvidas com violência, sob a pena de desmoralização social da família ofendida ou em particular daquele que não reagia da maneira que era socialmente esperada (WOLFF, 1999, pp. 195-241).

Diante do exposto, este estudo pretende abordar tais questões tendo como foco discutir aspectos relacionados aos costumes e valores em conflito com a ordem legal então vigente no Acre do período territorial, entre 1904 e 1920. As fontes primárias utilizadas foram os jornais A Reforma, Folha do Acre, Alto Purus, O Município e O Cruzeiro do Sul, que circularam nos quatro Departamentos do Território Federal do Acre: Alto Acre (sede em Rio Branco); Alto Purus (Sena Madureira); Alto Juruá (Cruzeiro do Sul) e Alto Tarauacá (Tarauacá). Alem disso, fizemos uso de algumas das obras literárias mais conhecidas regionalmente que abordam aspectos apontados como foco de análise.

\section{Estupros e defloramentos nos jornais acreanos}

Na cidade de Rio Branco (sede do Departamento do Alto Acre) o jornal Folha do Acre, no ano de 1920, publicou uma pequena nota cujo titulo era "Vão se cazar". O teor dizia que o delegado de polícia havia comunicado ao juiz da comarca ter remetido à promotoria pública o inquérito policial 
sobre o defloramento de Maria Ferreira Xavier, cometido por Luiz Baptista do Nascimento no seringal Belo Jardim, "sem mais formalidades legais visto o offensor e a offendida desejarem cazar um com o outro" (FOLHA DO ACRE, 20-03-20). Muitas vezes, o intercurso carnal e sua divulgação era algo combinado entre réu e vítima para que a justiça obrigasse o acusado a casar-se com a ofendida. Isso ocorria quando a família da mulher, geralmente virgem, não aceitava o seu relacionamento com a pessoa escolhida pelos pais ou responsáveis., como já dissemos. Uma forma de confrontar as imposições e controle familiar era tornarse "desonrada" perante a família e a sociedade local, algo que se reparava com o casamento respaldado no Código Penal em vigor à época e autorização da família da mulher dita ofendida. Mas nem todos os casos, na verdade a grande maioria, se enquadravam no exemplo que acabamos de explicitar.

Como é o caso ocorrido em um período próximo ao supracitado e que foi publicado no jornal tarauacaense (Departamento do Alto Tarauacá) A Reforma, dando conta da diligência ao rio Muru conduzida pelo delegado Leôncio Luís Rodrigues. Este delegado foi até ao Seringal Paraízo para averiguar a denúncia do defloramento e estupro de duas menores cometidos pelo próprio pai das vítimas, identificado pelo nome de Raimundo Nonato. A informação sucinta do periódico esclarece que o acusado teria fugido em direção ao Purus (não fica claro se foi para o rio ou Departamento vizinho), levando uma das vitimas (A Reforma, 26-10-19). Temos aqui, além das incursões nos crimes apontados, um caso de duplo incesto realizado pelo genitor de duas meninas sob sua criação e proteção. O incesto não era tipificado como crime no Código Penal de 1890 e nem a Constituição Federal de 1891 tocava neste assunto. Portanto, o chamado tabu do incesto era algo que se vinculava somente a impedimentos de ordem social, moral e religiosa.

Estudos como o de Christina Wolff (1999) demonstram que havia muitos casos de incestos, estupros e defloramentos na região do Alto Juruá, que segundo ela se combinavam de diversas maneiras. Esta era certamente uma realidade que poderia ser encontrada de forma semelhante nos outros departamentos do Território Federal do Acre nas primeiras décadas do século XX. Os incestos eram casos que envolviam parentes consangüíneos (irmãos, pais, 
tios, filhas e sobrinhas). Já os estupros podiam envolver as mesmas pessoas anteriores e incluir vizinhos, amigos e estranhos no crime de violência carnal forçada contra a mulher. Mas do ponto de vista social e dos valores de masculinidade, a fronteira entre estupro e defloramento era muito tênue. No caso de estupros causados por parentes, muitos dos casos não vinham à tona por medo da vítima em denunciar, diz esta autora: medo físico, psicológico. Além disso, a estrutura familiar de caráter patriarcal predominante definia quem detinha o poder e como se constituíam os papéis sociais de gênero.

Em Sena Madureira, sede do Departamento do Alto Purus, o jornal O Alto Purus, em 1908, deu publicidade a um ofício da prefeitura local, do dia 24 de janeiro, onde o capitão José Negreiros de Falcão, residente na localidade "Campo Ozório", nas margens do rio Iaco, comunicava ter prendido o indivíduo José Gomes por ter este cometido estupro atacado de "suas faculdades mentaes" e pedia que a prefeitura providenciasse uma passagem fluvial para que o acusado fosse deslocado até a cidade para ser julgado (O ALTO PURUS, 0803-08). Na linguagem atribuída ao militar, já percebemos que há claramente uma atenuação do crime praticado pelo fato do acusado estar "alterado" mentalmente. O já citado Código Penal, em seu artigo 27, parágrafo $4^{\circ}$, lidava com dispositivos que serviam como atenuantes para determinados crimes cujos agentes eram os homens: havia a alegada "defesa da honra" masculina e a recorrente "privação de sentidos" como elementos de minoração da possível pena ser aplicada ao reú.

Outro aspecto que merece destaque é que essas distâncias entre a sede do Departamento e localidades na floresta situadas, muitas vezes, há dias de viagem dos órgãos público (justiça e polícia), faziam com que o cumprimento dos mandados de prisões fossem extremamente difíceis: fuga do acusado que se internava em locais mais distantes de onde morava, falta de estrutura do Estado para fazer cumprir a lei (poucos policiais e oficiais, recursos financeiros para passagens e alimentações, embarcações) e até o fato de muitos crimes "contra a segurança da honra e honestidade da famílias e do ultraje público ao pudor" fossem silenciados pelos medos e convenções sociais. Para este último aspecto, ou por descrença na justiça ou por se preferir lavar a honra "com sangue", resolvendo as pendengas existentes no âmbito privado e não através 
do Estado e seu arcabouço legal muito deficiente no Acre Federal dos primeiros anos do século XX.

Outro caso narrado com mais detalhes pelo mesmo jornal, apareceu em 1911 (O ALTO PURUS, 11-09-11). Frederico Martins foi denunciado pelo promotor público da cidade de ter deflorado Maria Benedicta Serra, algo não foi aceito pelo juiz substituto J. Alves de Castro. Na sua peroração o juiz afirma que mesmo o exame de corpo delito constatando o rompimento do hímem da vítima, não tinha como caracterizar se isso foi antes ou depois da menoridade dela.

Algo que tornava difícil precisar a ocorrência do crime de defloramento, pois já havia se passado mais de seis meses segundo atesta esta autoridade. Fica patente que as autoridades não apontam para violência carnal e nem estupro, pareciam consensuar que Maria Benedita teria consentido a relação sexual e como não havia forma de precisar se isso teria ocorrido antes ou depois de ter completado dezoito anos, o juiz na dúvida beneficia Frederico Martins. O juiz substituto acusa ainda o promotor de ter exorbitado em suas funções e anula todo o processo "por incompetência do Ministério Público".

Mas este mesmo caso volta à tona novamente em algumas edições depois d'O Alto Purus (O ALTO PURUS, 11-09-11), onde o caso de defloramento é reaberto e tratado por um novo juiz chamado Daniel Carneiro. Segundo o magistrado, a casa em que morava a menor Maria Serra era frequentada por vários rapazes e após serem ouvidas todas as testemunhas, inclusive a mãe da vítima, não havia provas irrefutáveis contra o acusado Frederico Martins. E uma das testemunhas teria dito em juízo "não saber se a ofendida fora sempre tida e havida como moça virgem", afirmação que contribuía para esvaziar a suspeição sobre o único acusado. E que "alem da reunião de homens à noite na casa da menor, vivia esta desacompanhada pelo mercado e outros lugares públicos trocando pilherias licenciosas com pessoas do povo, achando-se desde algum tempo de casa aberta nesta cidade".

A culpa acaba sendo atribuída à Maria Serra pelas muitas "facilidades" que ela teria dado aos homens quando não se comportou de acordo com o considerado adequado pelos valores morais hegemônicos à época. 
Nesta direção, o estudo de Cristiana Schettini (2006) aponta que “o status moral de mulheres era estabelecido através da noção de honra, associada ao recato e a espaço privado, qualquer atuação delas no espaço público as deixava vulneráveis a constantes julgamentos morais" (SCHET'TINI, 2006, p. 22). No caso tratado aqui, esses aspectos são inclusive corroborados pela justiça.

É nesta direção que o juiz sustenta então que diante “das facilidades de semelhante viver da menor, assediada por outros homens, nenhuma razão de justiça pode aconselhar" à condenação do único réu apontado no processo. O juiz usa o exame de conjunção carnal a favor da absolvição ao destacar mais uma vez que não era possível precisar se o defloramento de Maria Serra era recente ou antigo. Com isto, “despronúncia” então o acusado Frederico Martins que se livra de culpa no caso em questão.

O caso que passamos a tratar é o de rapto, ocorrido no Departamento do Alto Purus em 1912 (O ALTO PURUS, 27-04-13). De acordo com o periódico municipal, no dia 11 de abril foi prestada queixa por Martha Maria da Conceição contra Francisco Nogueira de Queiroz, este mais conhecido pelo apelido de Piloto, que segundo a denunciante alguns dias antes o acusado teria raptado sua filha de 13 anos chamada Edwiges Damasceno. A mãe narra que Piloto raptou sua filha da colocação Salvação e desta localidade fugiu para a cidade de Sena Madureira. Segundo o jornal, "foi feito pela polícia o exame necessário, verificando-se que a menor achava-se de fato desvirginada, pelo que foi efetuado o casamento por intermédio da polícia”. Mas uma vez se evidencia que o rapto conjugado com a conjunção carnal era um ato planejado em que os fugitivos jogavam com o aspecto legal a favor principalmente do acusado e muitas vezes da própria vítima que colaborava e incentivava o crime de rapto.

No entanto, devemos entender que a relação entre um homem adulto e uma menor, como ocorria na maioria das vezes nestes casos, não era pautada em experiências de vidas e estruturas psicológicas, sociais e políticas igualitárias. Muitos menos os papéis sociais masculinos e femininos se equivaliam na sociedade brasileira e acreana da virada do século XIX para o XX.

Outro caso em Sena Madureira que também resulta em casamento foi o defloramento da menor indígena identificada apenas por Pirá, 
com "menos de 10 anos presumíveis" (O ALTO PURUS, 29-03-14). O apelante é o próprio acusado, chamado de João da Cruz Correia, que recorre à justiça solicitando casar-se com a menor "ofendida". O juiz Alberto Diniz, no dia 10 de janeiro de 1914, então concede a solicitação explicando que "não há lugar a imposição da pena quando ao defloramento seguir-se o casamento". A idade era algo que as autoridades pareciam não levar muito em conta, pois "considerando a ofendida ter menos de 10 anos não é obstáculo para a realização do casamento, pois o decreto 181, de 1890, manda que se faça o casamento, podendo o juiz determinar a separação de corpos até que a nubente menor complete a idade legal". Alguns dias depois, em 25 de fevereiro o mesmo juiz dá seu despacho final ao mandar que "se ordene as providencias necessárias a fim de se efetuar o casamento do apelante João da Cruz Correia com a menor Pirá”. As violências físicas e psicológicas das mulheres vitimadas por defloramentos ou estupros, pareciam aos olhos das autoridades e legislação da época, se resolverem com simples casamento assumido pela parte masculina como reparo à honra feminina.

Contudo, a resolução legal do caso em tela toma um rumo inusitado ao que foi decidido pelo juiz Alberto Diniz e frustra o intento do acusado de defloramento, quando o novo juiz R. Araújo Jorge toma conta do caso:

Tornando-se impossível o cumprimento do acordam por ter um individuo, que se dizia encarregado da catequese de índios no Acre, conduzido a menor para Manaus, foi requerido originariamente o habeas corpus por estar o paciente preso em virtude de sentença do juiz de direito e não se ter realizado a reparação do dano por motivo de força maior: desaparecimento da ofendida e seu consequente falecimento em Manaus. (...). Se o crime não foi reparado, existe ainda. Consequentemente, a sentença da primeira instancia subsiste ainda, tais os termos do acordam. Dele não consta a reforma da sentença, por ele não foi o impetrante absolvido. Ao ser concedido o habeas corpus, dar-se-a o absurdo de vermos um individuo, convencido do crime de estupro e condenado por juiz competente, em processo regular, ser posto em liberdade; o que não pode deixar de ser lamentável e de consequências funestas visto como os crimes contra o pudor e contra a honra da mulher são justamente os que mais são acoçoroados pela 
impunidade. Por todos esses motivos, neguei o habeas corpus (O ALTO PURUS, 29-03-14).

Assim, ficamos sabendo que João da Cruz só não consegue seu intento como acaba sendo preso após desaparecimento e posterior falecimento da menina indígena que foi levada à Manaus por um aludido catequizador de índios, o que acaba inviabilizando a possibilidade do casamento. Seu advogado entra então com pedido de habeas corpus justificando que o não cumprimento da suspensão da pena (dada pelo casamento) não ocorreu por vontade de seu cliente. Contudo, tal pedido é negado pelo juiz Araújo Jorge ao destacar que a morte da vítima não anulava o crime de estupro praticado por João da Cruz. E realça ainda que tal atitude visava também punir o acusado por algo que geralmente não levava a maiores consequências jurídicas e penais para aqueles que cometiam tais crimes.

O rapto e estupro de mulheres indígenas muito jovens é algo bastante discutido no âmbito das ciências sociais que tratam da formação dos seringais na Amazônia conjugada com a expulsão e ocupação de terras habitadas por indígenas. No caso do Acre, temos os trabalhos de Marcelo Iglésias, Mariana Pantoja e Terri do Vale Aquino (1977). São respectivamente Os Kaxinawá de Felizardo: correrias, trabalho e civilização no Alto Juruá (2010); Os Miltons: cem anos de história nos seringais (2008) e Kaxinawá: de seringueiro “caboclo" a peão "acreano" (1977), que mostram as múltiplas relações interétinicas forçadas, compulsórias e extremamente violentas envolvendo indígenas e os migrantes das frentes econômicas e expansionistas.

\section{A Literatura e os crimes contra a honra e gênero: ficção como expressão do real}

A literatura regional, que alguns irão chamar de "literatura dos seringais", vai tratar com frequência de aspectos sociais ligados às questões de gênero, honra e sexualidade nos seringais amazônicos e acreanos em narrativas situadas muito próximas ao recorte temporal adotado no presente artigo: ou seja, últimos anos do século XIX e anos iniciais do século seguinte. Seus autores geralmente foram agentes públicos ou profissionais liberais que viveram e transi- 
taram nos ambientes que descreveram ou então ouviram de segunda mão muito do irão colocar nas tramas de suas obras literárias.

No livro Seringal, de Miguel Ferrante, publicado em 1972, temos um caso de estupro cometido pela personagem chamada Carlinhos, filho do prefeito e protegido do seringalista chamado coronel Fábio. A vítima de nome Paula tem somente doze anos de idade e torna-se o amor e alvo de compaixão de Toinho, afilhado do coronel Fábio. O dono seringal e homem de poder do lugar, finda sendo assassinado pelo seu afilhado, que busca ao longo da trama vingança pela morte de Paula que ele atribui ser culpa do seu padrinho que fechou os olhos e nada fez para reparar o erro cometido por Carlinhos. Vemos neste pequeno resumo explicitadas as relações hierárquicas de poder baseadas no mandonismo e nas redes de proteções de classe. Os subordinados, os fracos, em situações limites respondem com violência e determinação nas suas vinganças contra os poderosos do lugar. $\mathrm{Na}$ realidade dos seringais essas revoltas trágicas contra os patrões não eram tão estranhas, como já foi demonstrado por Chistina Wolff (1999) ao chamar essas práticas corriqueiras de "linguagens da violência".

Em Alberto Rangel, autor de Inferno verde lançado em 1908, a cabocla Maibi é uma das poucas mulheres existente na localidade chamada seringal Soledade, onde se passa parte da trama do romance. Ela é usada como moeda de troca pelo patrão de seu marido, tenente Marciano. O seringueiro Sabino da Maibi é devedor de uma grande quantia no barracão, quando se vê obrigado a ceder sua esposa no momento em que a sua dívida é assumida por outro seringueiro chamado Sérgio, que tinha fama de trabalhador e pessoa com saldo no barracão. Desgostoso com o "negócio" forçado e com saudades da cabocla, Sabino mata Maibi e ela então se transfigura simbolicamente na própria Amazônia: explorada, abusada, violentada e objeto de desejo de homens aventureiros.

Em Coronel de barranco, romance situado na virada do século XIX para o XX e escrito por Cláudio de Araújo Lima (publicado na década de 1970), temos o dono do seringal Santa Fé chamado coronel Cipriano, que mata a prostituta de nome Conchita com quem tivera uma relação amorosa após tê-la encomendado junto a um regatão sírio para viver no seu seringal. Acontece que após chegar no seringal, apesar da meia-idade, Conchita se torna "grande 
atração do seringal Santa Fé. A senhora para uns, o casquinho para outros, o bucho velho para muitos poucos (...) sobre quem se concentravam os interesses eróticos daquela sociedade sem mulheres” (LIMA, 2002, p. 256).

Ao despertar tantos interesses, Conchita acaba fugindo com o guarda-livros do barracão chamado Antoninho após uma viagem de Cipriano para Manaus a negócios. Ao saber da fuga, torna-se questão de honra a vingança por parte de Cipriano por ter sido enganado por uma prostituta. Este "acerto" ocorre algum tempo depois em Manaus quando ela é encontrada. Coronel Cipriano representa a figura de poder por excelência nas vastidões dos seringais, que dita as normas e resolve questões conflituosas em terras e gentes sob seu domínio. Sua sede de vingança é mais centrada na traição de Conchita do que nos procedimentos de seu antigo empregado, que na trama do livro não aparece sendo perseguido ou castigado. Raptos eram mais tolerados do que a traição feminina no arcabouço dos valores não escritos da sociedade dos seringais.

Há ainda a moça Rosinha prima do narrador Matias Albuquerque, que se torna gerente e dono do seringal Santa Fé após a prisão do coronel Cipriano pelo assassinato de Conchita. Rosinha foi o grande amor de Matias quando jovem e vivia junto com seu tio Amâncio no seringal deste. Sua prima ao chegar no seringal vinda de um convento, se confessa apaixonada pelo jovem Matias e conta a ele ter sido assediada por um seringueiro chamado Sandoval que queria se casar com ela. Em seguida ela fica grávida e sem declarar quem é o pai do seu filho, acaba sendo assassinada durante uma missa dominical quando a pequena igreja próxima ao barracão é invadida pelo seringueiro enciumado, que após matar Rosinha a punhaladas se suicida.

Ao se confessar apaixonada por Matias Albuquerque, temos a hipótese de Rosinha querer fazer um arranjo intrafamiliar para resolver sua situação de futura mãe solteira, que logo seria descoberta e se tornaria motivo de vergonha para todos os parentes. Como realça Wolff, os casamentos endogâmicos tinham ainda como pressuposto, em certas situações, a manutenção do patrimônio familiar que ficaria preservado de fragmentação e cobiça de elementos externos. Podemos ainda asseverar da resistência familiar em permitir que a sobrinha do patrão casasse com um simples seringueiro, que certamente sabia 
desta barreira quase intransponível e ao matá-la é como se dissesse à todos: "se não for minha, não será de mais ninguém".

\section{Considerações finais}

Neste breve artigo intentamos discutir alguns aspectos relacionados com os chamados crimes contra a honra, crimes estes que conjugavam elementos de ordem legal e práticas culturais fortemente impregnadas pelos valores patriarcais. $\mathrm{O}$ atual estado do Acre teve sua formação marcada por migrantes de diversos quadrantes, que atraídos pela riqueza extrativa da borracha natural foram ocupando terras e expandindo fronteiras étnicas, territoriais, lingüísticas, culturais e políticas. Confrontos e interações de múltiplas características foram se formatando no interior das florestas, margens de rios e nos núcleos urbanos que irão se formar.

Práticas cotidianas e normas baseadas nos costumes passam a ser regulados pelo poder legal que aos poucos e forma errática vai se implantando com a chegada do Estado a partir de 1903 com a assinatura do Tratado de Petrópolis celebrado entre Brasil e Bolívia, que cede a região acreana definitivamente ao Brasil. A chegada da justiça e da ordem legal, busca regular modos de vidas e práticas bastante arraigadas nas formas de sociabilidades então preponderantes. Indicar as formas de bem viver, ordenamentos, disciplinas e punições passam a ser prerrogativas do Estado.

Mas no interior das florestas, nos altos rios e seringais a vida continuou ainda por muito tempo centrada nos costumes e valores tradicionais. Centrada em relações hierarquizadas de poder, distinção dos papeis de gêneros, aspetos raciais, status social e econômico. E que também apareciam corriqueiramente em jornais locais quando divulgavam crimes de raptos, assassinatos passionais, estupros, defloramentos e outros correlatos envolvendo a chamada "honra".

\section{Abductions, Deflorations, violence AND POWER RELATIONS IN ACREAN AMAZON (1904-1920)}

ABSTRACT: This work attempts at approaching the issue of criminality in the 
Federal State of Acre, mainly in relation to the so-called crimes against honour and morality. Newspaper reports, criminal trials and literary works are used as primary sources. Regardless of whether they are fictional or real, these crimes bear the mark of power relations between genders, typically in case of disputes between men for the same woman, or in vendettas by male parents to defend the injured honour of women from their family, among other practices related to a society characterised by "rituals of masculinity", as claimed by McClintock (2010) when talking about colonial and imperial contexts. Therefore, the analysis of these issues in border areas, which are characterised by frequent encounters and clashes between people coming from many places, with different interests and backgrounds, reveals practices and identities often submerged beneath the surface of traditional narratives.

KEYWORDS: Violence. Crime. Woman. Acre. Identity

\section{Referências}

AQUINO, T. V. Kaxinawá: de seringueiro "caboclo" a peão “acreano”. Dissertação de mestrado. PPGAS - UNB, 1977.

A REFORMA. Diligencia policial ao Muru, 26 de outubro de 1919, n. 77, p. 03.

FARIA, A. B. Annotações theorico-práticas ao Código Penal do Brazil. Volumes I e II, $2^{a}$ edição, Rio de Janeiro: Francisco Alves, 1913.

FAUSTO, B. Crime e cotidiano: a criminalidade em São Paulo (1890/1924). $2^{a}$ edição. São Paulo: Edusp, 2001.

FOLHA DO ACRE. Vão se cazar, 20 de março de 1920, ano X, n. 305, p. 01.

IGLESIAS, M. M. P. Os Kaxinawá de Felizardo: correrias, trabalho e civilização no Alto Juruá. Brasília: Paralelo 15, 2010.

O ALTO PURUS. Jurisprudencia, 29 de março de 1914, n. 286, p. 02.

O ALTO PURUS. Jurisprudencia, 18 de janeiro de 1914, n. 35, p. 02.

O ALTO PURUS. Secretaria da prefeitura, 8 de março de 1908, n. 03, p. 02.

O ALTO PURUS. Justiça local, 11 de setembro de 1911, n. 167, pp. 03-04.

O ALTO PURUS. Justiça local, 15 de outubro de 1911, n. 171, pp. 03-04.

O ALTO PURUS. Ocorrências, 27 de abril de 1913, n. 239, p. 03.

LIMA, C. A. Coronel de Barranco. $2^{\text {a }}$ ed. Valer: Manaus, 2002.

McCLINTOCK, A. Couro imperial: raça, gênero e sexualidade no embate colonial. Tradução de Plínio Dentzien. Campinas: Edunicamp, 2010. 
PANTOJA, M. C. Os Miltons: cem anos de história nos seringais. $2^{\mathrm{a}}$ edição. Rio Branco: Edufac, 2008.

RANGEL, A. Inferno verde: scenas e scenários do Amazonas. São Paulo: Arrault, 1927. SCHETTINI, C. Que tenhas teu corpo: uma história social da prostituição no Rio de Janeiro das primeiras décadas republicanas. Rio de Janeiro: Arquivo Nacional, 2006.

SILVA, F. B. Moral e cotidiano: vadiagem e prostituição no Departamento do Alto Acre (1904/1920), In: MUIRAQUITÃ, revista de Letras e Humanidades do Programa de Pós Graduação em Letras: Linguagem e Identidade, PPGLI/UFAC. Rio Branco - Acre, volume 2, n. 1, 2013, pp. 97-119.

WOLFF, C. S. Mulheres da floresta: uma história do Alto Juruá, Acre (1890-1945). São Paulo: Hucitec, 1999.

Data de recebimento: 16/07/2014

Data de aceite: 19/08/2014 